\title{
Controlled Evaluation of a Physical Activity Intervention for Senior School Students: Effects of the Lifetime Activity Program
}

\author{
David Lubans ${ }^{1}$ and Kathy Sylva ${ }^{2}$ \\ ${ }^{1}$ University of Newcastle and ${ }^{2}$ University of Oxford
}

\begin{abstract}
This study describes the development, implementation, and evaluation of a structured physical activity intervention designed for high school students (years 11 and 12). A sample of 78 students was randomly allocated to control or intervention conditions for a period of ten weeks. Students in the control group $(n=40)$ participated in unstructured physical activity in a health and fitness center. Students in the intervention group $(n=38)$ participated in a ten-week structured health and exercise program based on Bandura's social learning theories. At the initial posttest, a number of statistically significant group differences were found using analysis of covariance. The intervention group reported more physical activity and improved exercise self-efficacy in comparison to the control group. At the 3-month follow-up, no statistically significant differences in physical activity were found. Results from this study suggest that a well-organized exercise-based program can be effective in increasing physical activity behavior of adolescents on a short-term basis.
\end{abstract}

Key words: adherence, exercise, adolescents

Among adults, physical inactivity is associated with a range of lifestyle diseases, including diabetes, obesity, and cardiovascular disease (U.S. Department of Health and Human Services, 1996). Although documenting the consequences of physical activity during youth is challenging (Baranowski et al., 1992; Cavill, Biddle, \& Sallis, 2001; Welk, Corbin, \& Dale, 2000), evidence is accumulating that the onset of many chronic diseases of adulthood lies in youth (Boreham, Twisk, Savage, Cran, \& Strain, 1997; Twisk, Kemper, van Mechelen, Post, \& van Lenthe, 1998). Unfortunately, physical inactivity has become a global problem, with more than half of the world's population not achieving modest physical activity recommendations (World Health Organization, 2005). It is of particular concern that physical activity levels decline drastically during adolescence. This decline

${ }^{1}$ Faculty of Education \& Arts, University of Newcastle, Callaghan Campus, NSW 2308 Australia, and ${ }^{2}$ Department of Educational Studies, University of Oxford, 15 Norham Gardens, Oxford OX26PY U.K. 
in physical activity has been identified from longitudinal studies (Aarnio, Winter, Kujala, \& Kaprio, 2002; Aaron, Storti, Robertson, Kriska, \& Laporte, 2002; Kelder, Perry, Klepp, \& Lytle, 1994; Maia et al., 2001) and U.S. and U.K. national surveys (Gordon-Larsen, Nelson, \& Popkin, 2004; Sproston \& Primatesta, 2003).

Despite the knowledge that the age-related decline in physical activity is steepest between the ages of 13 and 18 (Sallis, 2000) or grades 9 through 12 (U.S. Department of Health and Human Services, 2000), the majority of school-based physical activity interventions have been conducted in primary schools (Biddle, 2001). Few interventions have been completed in secondary schools and even fewer have involved students in their final school year. This may be due to competition for curriculum time, lack of student interest, or a combination of reasons. Despite these difficulties, recent secondary school interventions - New Moves (NeumarkSztainer, Story, Hannan, \& Rex, 2003; Neumark-Sztainer, Story, Hannan, Tharp, \& Rex, 2003), Project FAB (Schneider-Jamner, Spruijt-Metz, Bassin, \& Cooper, 2004), and the Lifestyle Education for Activity Program (Dishman et al., 2004, 2005) - have demonstrated that secondary schools are appropriate settings for intervention.

This study describes the development and evaluation of the Lifetime Activity Program (LAP), a 10-week conceptual physical education program developed by the researchers with reference to Bandura's social cognitive theory (SCT) and self-efficacy theory (SET) (Bandura, 1977, 1986, 1997). The overarching aim of the LAP was to encourage positive changes in physical activity by increasing individual knowledge and the confidence to be active and by developing techniques to enhance social support for activity from friends. Social support has been identified as a potential determinant of youth physical activity behavior, and previous interventions have involved components to enhance family support for physical activity in primary schools (McKenzie et al., 1996; Saakslahti et al., 2004; Stevens et al., 2003; Vandogen et al., 1995), secondary schools (Simon et al., 2004) and environments other than in schools (Fitzgibbon, Stolley, Dyer, VanHorn, \& KauferChristoffel, 2002). Even though cross-sectional research has provided evidence for a positive relationship between social support and adolescent physical activity behavior (Prochaska, Rodgers, \& Sallis, 2002; Sallis, Taylor, Dowda, Freedson, \& Pate, 2002; Saxena, Borzekowski, \& Rickert, 2002), to the authors' knowledge, no previous school-based intervention has provided students with guidelines to augment peer support for physical activity.

\section{Methodology}

\section{Subjects}

The study methodology was approved by the University of Oxford's Department of Educational Studies Ethics Committee, and all students and parents/guardians provided informed consent. The study sample was drawn from high school students (aged 16-18) who had selected a health and fitness school sport option. Students involved in the study were of particular interest to the research community as they were individuals who elected to participate in a unit focusing on health and fitness, rather than the traditional team sports offered by the school. This was the only alternative available to students who did not wish to participate in the team 
sports option. From the target population of 105 students, 78 students volunteered to be involved in the LAP $(N=78)$. As there were considerably more girls in the eligible sample, before randomly allocating students to conditions, the sample was stratified by gender to ensure equal numbers of males and females in control $(n=$ $40)$ and intervention $(n=38)$ groups.

\section{Treatment conditions}

Constructs or determinants from Bandura's theories have been identified as important for understanding and intervening in health behavior (Baranowski, Perry, \& Parcel, 1997). Self-efficacy is central to Bandura's theories and deals with ideas of confidence, competence, and capability with reference to a specific task. In physical activity research, self-efficacy refers to an individual's confidence in their ability to be physically active on a regular basis (Nahas, Goldfine, \& Collins, 2003). Cross-sectional research has revealed a positive relationship between adolescent physical activity and self-efficacy (Allison, Dwyer, \& Makin, 1999; Garcia, Pender, Antonakos, \& Ronis, 1998; Strauss, Rodzilsky, Burack, \& Colin, 2001) and interventions based on Bandura's work have demonstrated that targeting self-efficacy can result in increased physical activity (Dishman et al., 2004; Neumark-Sztainer, Story, Hannan, Tharp et al., 2003; Sallis, Calfas, Alcaraz, \& Gehrman, 1999). The key constructs from Bandura's theories (self-efficacy, social support, perceived barriers, behavioral capability, and perceived benefits) were used to develop the content of the intervention. The program addressed socioenvironmental factors by providing the students with guidelines to increase their social support and guidance and modeling from the teacher. The guidelines included information regarding the selection of training partners, the planning of training sessions, the identification of perceived barriers, and the importance of motivation and feedback. These guidelines were revisited at the start of each LAP session, when students were given an opportunity to record the number of completed sessions and evaluate the relationship with their training partner. Behavioral factors were enhanced through goal-setting techniques, participation in exercise training, exercise program development, and the use of training diaries.

The program was designed for senior high school students (ages 16-18) and was delivered by a member of the research team. Owing to competition for curriculum time in high schools, the program involved minimal contact time with the researcher. Students in the intervention group met once a week, and each LAP session lasted approximately $90 \mathrm{~min}$. In addition to their scheduled session, students were encouraged to participate in 60 min of moderate to vigorous physical activity (MVPA) daily, as suggested by U.K. (Department of Health, 2004) and U.S. (U.S. Department of Health and Human Services \& U.S. Department of Agriculture, 2005) guidelines.

Each LAP meeting consisted of a didactic component and participation in practical lifetime exercise activities. The LAP curricular content included benefits of physical activity, physical activity guidelines, goal setting for fitness, types of cardiovascular training and heart rate zones, nutritional guidelines, components of physical fitness, principles of training, and weight training theory. The LAP practical content included a variety of cardiovascular activities, circuit training, a spinning class, and resistance training sessions. 
All sessions were completed in a health and fitness center that was used by the general public but was available free to students outside of normal classes. The health and fitness center consisted of a small pool, weights room, cardiovascular training room, and two dance/studio rooms used for various physical activities. Those in the treatment group were required to meet twice a week for the duration of the term. One session per week involved a researcher-led workout; for the other session, students completed their own training. The intervention group was divided by gender and met separately, on Tuesdays for girls and Thursdays for boys. Students in the control group were required by the school to attend the same health center and complete their own activity for two sessions of 90 min each week. Students in the control group were provided with access to weight training equipment, and cardiovascular equipment such as treadmills, ergometers, and stationary bikes. During the program, both control and intervention students were provided with exercise information cards with details of sample training sessions, abdominal exercises, warm-ups, and cool-downs. The training cards described sample workouts with examples of exercises, warm-ups, and cool-downs, along with suggested intensities. At the completion of the study, students in both groups were provided with an exercise training booklet.

\section{Measures}

All students in the study were asked to complete a questionnaire (Table 1) three times over the study period (in the first week of the program, in the final week of the 10-week program, and three months after the completion of the program). The study started in the second week of term and the baseline measurements were completed on the Monday or Tuesday of the first week of the study, before students started the intervention (study flow is illustrated in Figure 1). This enabled students to report their activity from a normal school week rather than the school holidays. All questionnaires were administered during roll call (registration). The questionnaire used in the study measured physical activity, along with a number of psychosocial factors. The physical activity behavior of the students was measured using the Oxford Physical Activity Questionnaire (OPAQ), which is a selfadministered, seven-day questionnaire designed to assess the MVPA of adolescent school students. The psychometric properties of the OPAQ were evaluated among a sample of 94 students with mean ages of 12.2 (year 7) and 13.8 (year 9). The OPAQ displayed strong test-retest reliability (0.63-0.91) and moderate concurrent validity $(0.45-0.63)$ through its relation to Caltrac movement counts.

It has been argued that the determinants of physical activity should be assessed along with the behavior itself (Baranowski, Anderson, \& Carmack, 1998; Calfas, Sallis, Oldenburg, \& Ffrench, 1997; Lewis, Marcus, Pate, \& Dunn, 2002; Sallis et al., 1999) because these are thought to mediate the targeted behavior change (Van Sluijs, Van Poppel, Twisk, Brug, \& Van Mechelen, 2005). As the current intervention was developed with reference to Bandura's social learning theories, the study was particularly interested in the mediating influences of exercise self-efficacy and peer support. Self-efficacy (Taylor et al., 2002) and peer support (Prochaska et al., 2002) were measured using existing scales, as were parent support for activity (Prochaska et al., 2002), body image (Hart, Leary, \& Rejeski, 1989), and perceived benefits of physical activity (Taylor et al., 2002). Students were also 


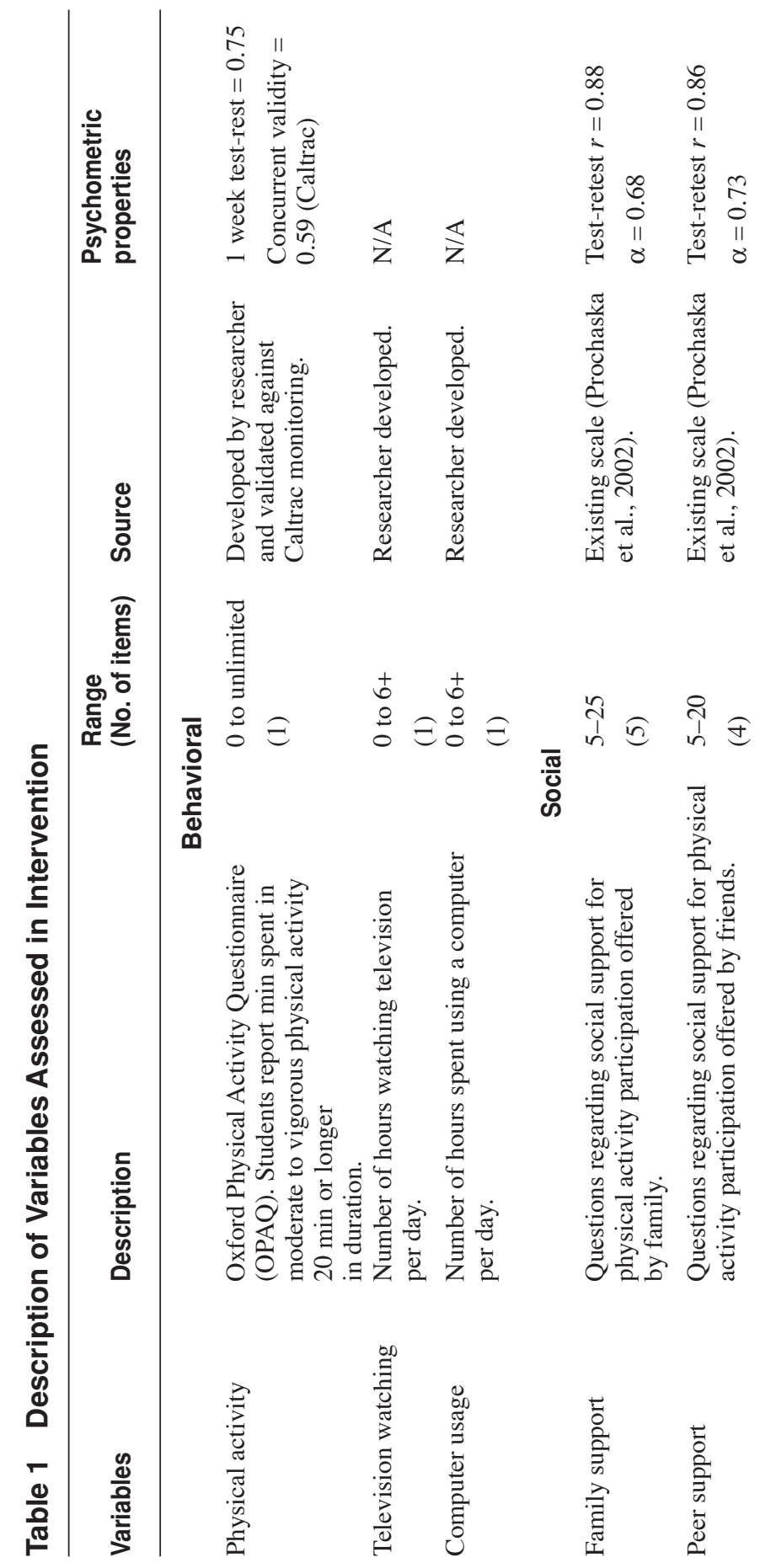


Lifetime Activity Program 257
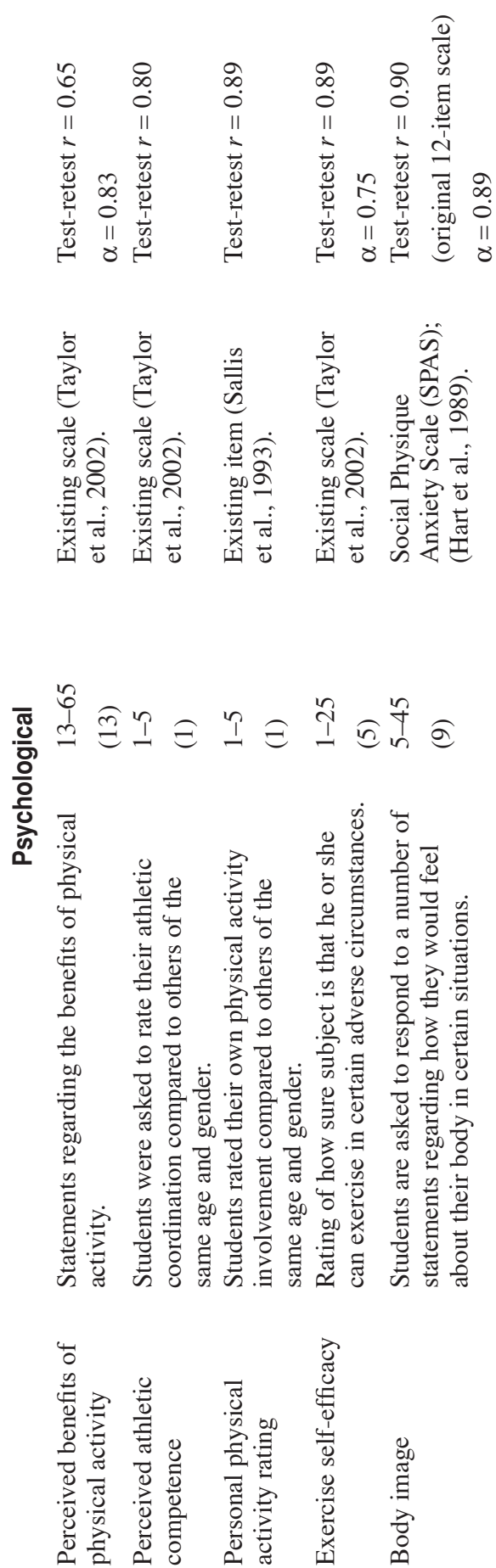


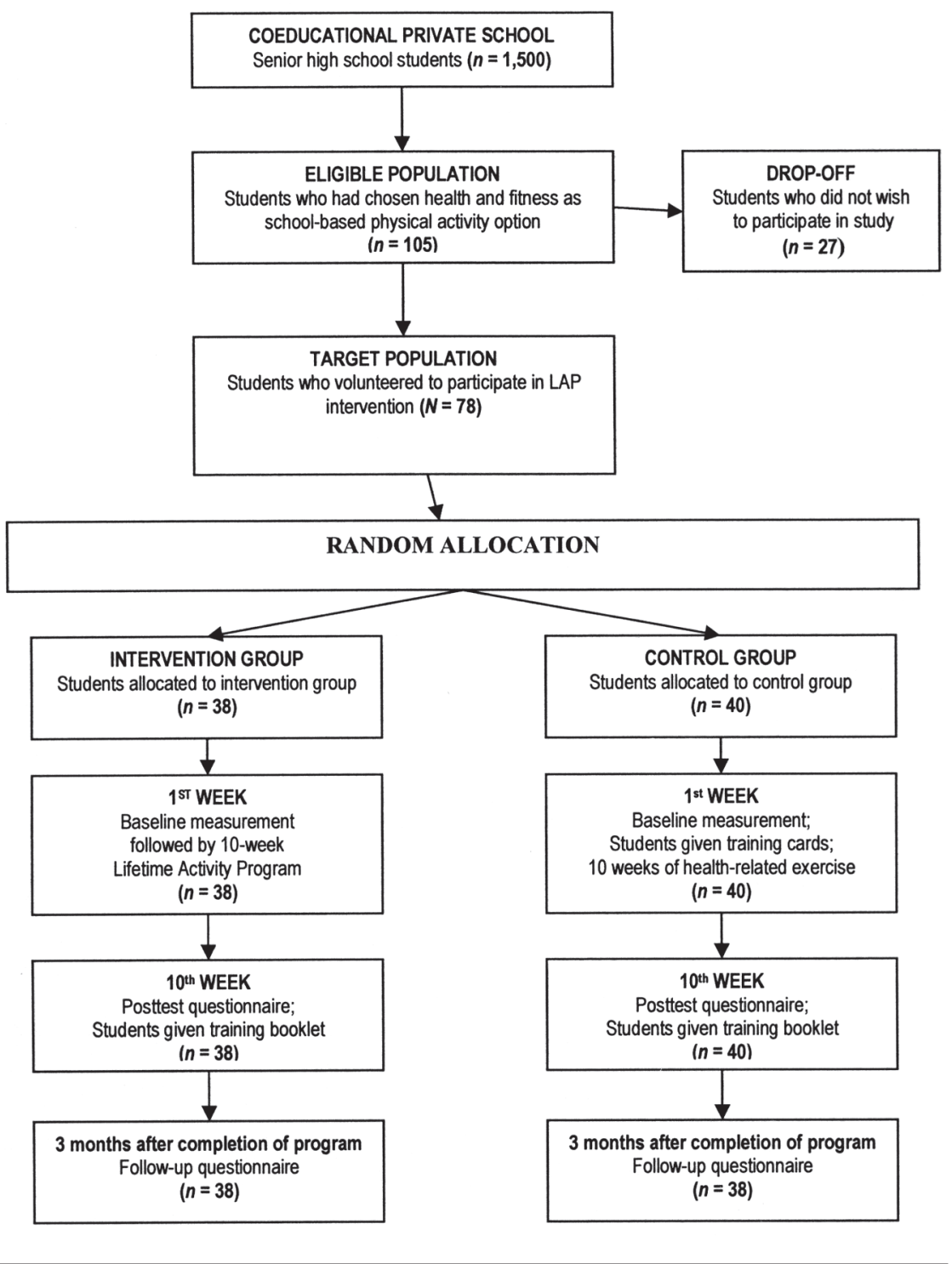

Figure 1 - LAP intervention design and sample flow.

asked to assess their own physical activity in comparison to others of their same age and gender (Sallis, Buono, Roby, Micale, \& Nelson, 1993). Although there is limited evidence that parent support, body image, and perceived benefits of activity work as mediators, these variables were measured to identify whether students responded more positively on all psychosocial outcomes, even those not targeted by the intervention. Furthermore, the intervention did not include a family component (i.e., parents were not required to provide additional support for activity) and it was 
hypothesized that this outcome would remain stable. It has been suggested that filter questions may help to overcome social desirability bias (Oppenheim, 1992). In this instance, these potentially redundant constructs were included in an attempt to identify this threat to validity.

\section{Data Analysis}

The data were analyzed using the SPSS software (version 12.0). Number of minutes spent in MVPA was calculated for each student along with totals for the various psychosocial scales. For the variables to be considered normally distributed, they were required to satisfy skewness and kurtosis criteria, whereby skewness/kurtosis divided by the standard error of skewness/kurtosis must be between -2 and +2 (National Institute of Standards and Technology \& Sematech, 2005). Variables that did not satisfy this criterion were successfully transformed using the log or square root functions.

The control and intervention groups were compared at baseline using independent sample $t$ tests. At posttest and follow-up, analysis of covariance (ANCOVA) was used to examine the effect of the intervention on the self-reported outcomes. All $t$ tests and ANCOVAs used a two-tailed hypothesis with the $\alpha$-levels set at $p<$ 0.05 . Marginally significant results were also reported $(0.05 \leq p \leq 0.10)$. Separate ANCOVAs were calculated for each of the variables at posttest and follow-up. In each of these equations, the ANCOVAs controlled for the baseline measurement (covariate) of the posttest or follow-up variable. Following the calculation of ANCOVAs, partial $\eta^{2}$ was used to establish the effect size or proportion of total variability attributable to each variable.

\section{Results}

A total of 78 students participated in the study; this included 48 girls and 30 boys distributed approximately equally across treatment and control conditions (Table 2 ). The average age of the students was 16.7 years. The majority of students lived with both parents $(77.2 \%)$ and had siblings (91.1\%). Most students $(83.3 \%)$ came from English-speaking households and like others in the school they were from predominantly high socioeconomic backgrounds. The students reported an average of 190 min of MVPA from the previous week and an average of 90 and 70 minutes per night of watching television and using a computer, respectively.

Independent samples $t$ tests used to compare the intervention and control groups at baseline revealed no statistically significant differences between the two groups. The intervention effects after 10 weeks are reported in Table 3 . At the end of the intervention, the time $\times$ condition interaction for minutes spent in MVPA was statistically significant $(F=9.69, p=0.001)$ and is illustrated in Figure 2. The time $\times$ condition interaction for the support variables were marginally significant $(0.05 \leq p \leq 0.10)$; family and peer support levels were higher in the intervention vs. the control group at postintervention. Students in the intervention group reported significantly better results for exercise self-efficacy $(F=5.92, p=0.02)$ and personal physical activity ratings $(F=8.16, p=0.01)$. There were no significant effects for perceived benefits of activity, perceived athletic competence, or body image between treatment groups $(p>0.10)$. 
Table 2 Descriptive Statistics at Baseline

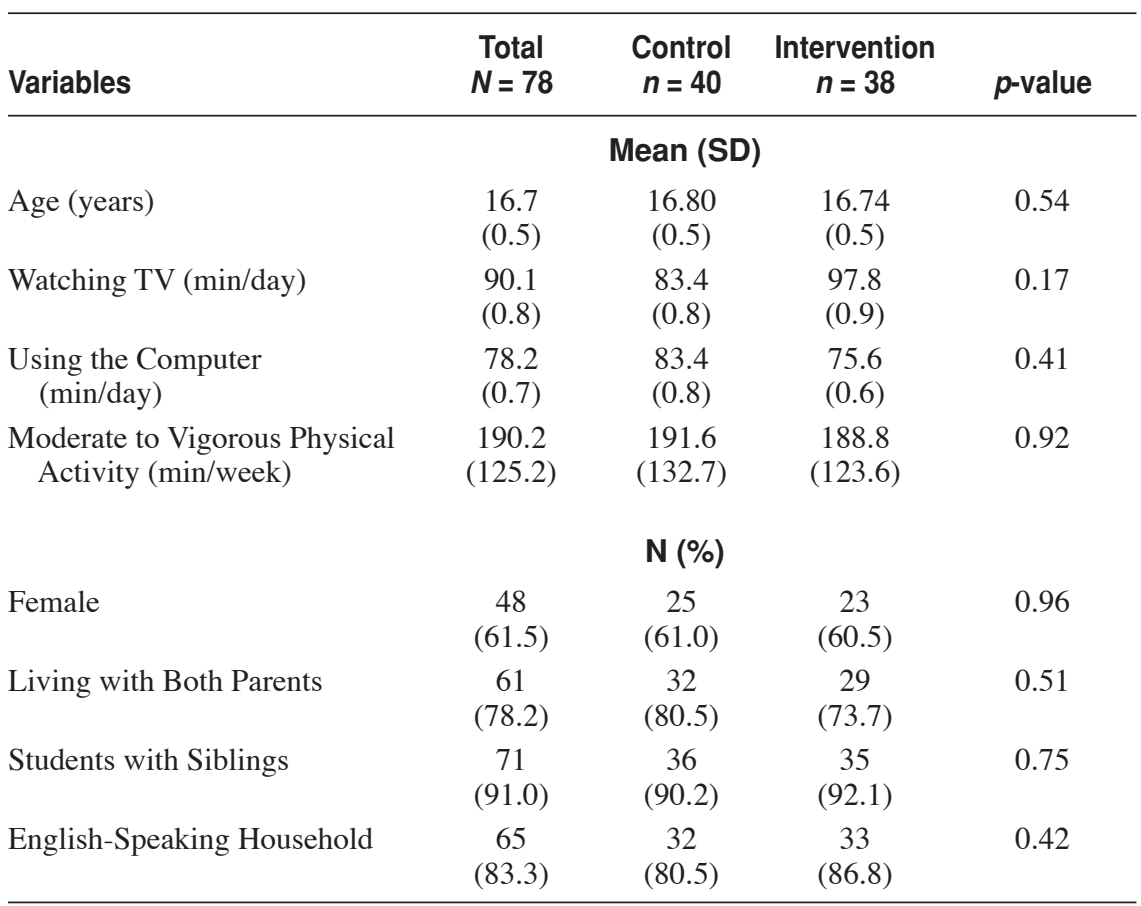

Note. The p-value was based on an independent samples $t$ test using a two-sided hypothesis.

The statistically significant difference in MVPA found between control and intervention groups at the end of the treatment was not present at the three-month follow-up (intervention mean $=289$ vs. control mean $=306, p=0.67$ ). Similar to the postintervention results, no statistically significant differences were found between groups for peer support or family support, although students in the intervention group (mean $=9.25$ ) reported more peer support than those in the control group (mean $=8.14)$ at the 3-month follow-up. Exercise self-efficacy $(F=4.26, p=0.04)$ and personal physical activity rating $(F=15.96, p<0.01)$ were significantly better in the intervention group. The remaining psychological variables (body image, perceived benefits of physical activity, and perceived athletic competence) did not differ significantly between the two conditions.

\section{Discussion}

The primary objective of this study was to examine the effects of the Lifetime Activity Program on adolescent physical activity behavior. It also sought to determine whether the intervention impacted the potential determinants of activity. Although the effect size was small $(d=0.12, p<0.01)$, at the end of the intervention period the treatment group reported spending $78 \mathrm{~min}$ more activity per week on average, 


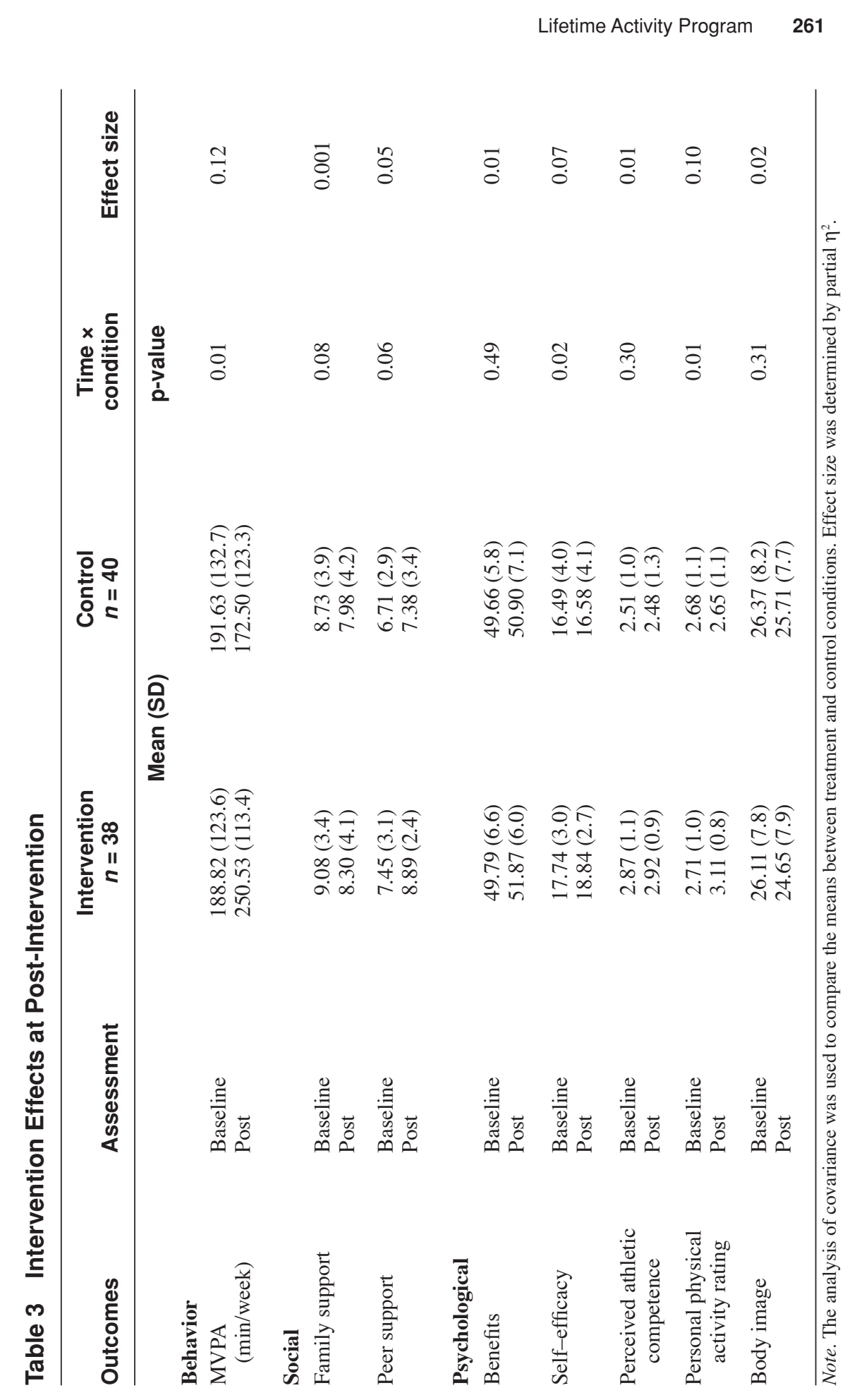




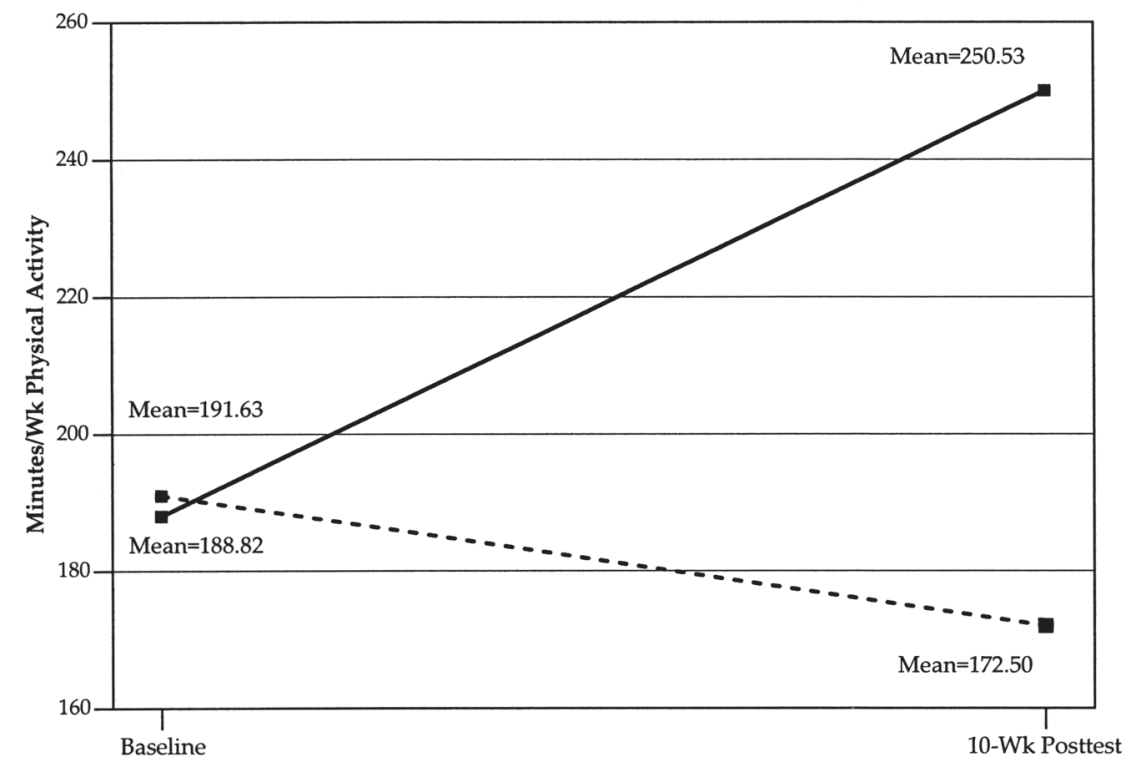

Figure $2-$ Intervention effects at 10 weeks posttest $(p=0.001)$. Dashed line indicates control; solid line indicates treatment.

compared to the control group. In addition to short-term changes in MVPA, students in the intervention reported better exercise self-efficacy and personal physical activity rating compared to those in the control group. Although some interventions with adolescents and young adults have found statistically significant improvements in MVPA at postintervention (Epstein, Paluch, Gordy, \& Dorn, 2000; Leslie, Fotheringham, Veitch, \& Owen, 2000; Patrick et al., 2001; Schneider- Jamner et al., 2004; Simon et al., 2004), others have not (Cardinal, Jacques, \& Levy, 2002; Fardy et al., 1996; Goldfine \& Nahas, 1993; Saelens et al., 2002). Furthermore, recent reviews of physical activity interventions identified the failure of most studies to include follow-ups (Hillsdon, Foster, \& Thorogood, 2005; Reilly \& McDowell, 2003; Timperio, Salmon, \& Ball, 2004) to determine whether behavior change was sustained. Those that have included longer-term follow-ups often find that group differences no longer exist (Calfas et al., 2000; Deforche, De Bourdeaudhuij, Tanghe, Hills, \& De Bode, 2004). Project Active Teens (Dale \& Corbin, 2000; Dale, Corbin, \& Cuddihy, 1998) provides evidence for the long-term effectiveness of physical activity interventions in the senior school years. Unfortunately, the results from Project Active Teens should be treated with caution as the study involved a quasi-experimental design, with the comparison group consisting of students who had transferred to the school after the intervention had been implemented.

In the current study, the activity levels of the intervention group were sustained at the three-month follow-up. However, the control group, had also increased their physical activity levels and there was no longer a statistically significant difference 
between the two groups. One possible explanation for this result is that the week in which the follow-up took place did not represent a normal school week, as the students had finished class and were preparing for exams. In addition, the final assessment took place in the summer, a time when students are often more active (Booth, Okely, Chey, Bauman, \& Macaskill, 2002; Rifas-Shiman et al., 2001). Considering evidence from previous studies examining the seasonality of physical activity and the current intervention's findings, the authors suggest that the winter months are an ideal time for intervention with the adolescent age group.

It has been argued that interventions are most effective when they alter the underlying factors that influence physical activity behavior (Trost, Owen, Bauman, Sallis, \& Brown, 2002). This appears promising as most studies that have evaluated the effects of interventions on potential mediators of behavior have found statistically significant changes (Dishman et al., 2005; Fardy et al., 1996; Goldfine \& Nahas, 1993; Patrick et al., 2001; Saelens et al., 2002; Simon et al., 2004; Van Sluijs et al., 2005). However, not all interventions have initiated positive changes in determinants of behavior (Calfas et al., 1997; Neumark-Sztainer, Story, Hannon, Tharp et al., 2003; Schneider-Jamner, Spruijt-Metz, Bassin, \& Cooper, 2004), and changes in behavior do not always accompany changes in self-reported variables. The current study found that only one potential mediator of MVPA (self-efficacy) was impacted by the intervention. Even though changes in personal physical activity rating were sustained after three months, this variable should only be considered as a behavioral self-report, not a potential mediator of behavior. There were no statistically significant differences between groups in any of the other psychosocial variables, despite the intervention's focus on peer support. However, marginally significant differences were found for peer support at postintervention and three-month follow-up. One possible explanation is that the intervention did not do enough to improve social support from peers or to change their perceptions about support from others.

Reilly \& McDowell (2003), in their review of physical activity interventions, concluded there is a lack of simple, effective, and generalizable interventions. Because individuals making decisions about the adoption of evidence-based physical activity programs can rarely choose intense interventions delivered by highly trained personnel in controlled settings (Dzewaltowski, Estabrooks, \& Glasgow, 2004), programs should be realistic and situation specific. School-based physical activity promotion programs should be suitable for the school environment and designed to be implemented by physical education (PE) teachers. These considerations influenced the design of the LAP, which included student workbooks and an easy-to-follow teacher manual. The results of this study provide evidence that physical activity interventions can be implemented in the final years of high school and that programs need not be intensive and time consuming to be effective on a short-term basis.

\section{Considerations}

Limitations of the study include a reliance on self-reported data, participant selection criteria that may limit external validity, and the possibility of treatment diffusion. Although the study may have benefited from the use of a physical measurement of MVPA (e.g., accelerometer, heart rate monitor, pedometer), these devices have 
their own limitations. Despite suggestions that self-report methods are unsuitable for use with younger children (Kohl, Fulton, \& Caspersen, 2000; Sallis \& Owen, 1999), the students involved in the LAP study were older adolescents, who are capable of recalling physical activity behavior at a satisfactory level.

Because students involved in the LAP evaluation were aware of their treatment allocation, this was a potential threat to the validity of the findings. In an attempt to overcome respondent bias, the researcher provided the control group with exercise information through the use of exercise cards at the start of the study and training booklets at the completion of the intervention. Although a small degree of socially desirable reporting cannot be completely discounted, the intervention group did not report more favorably on all variables, only those that were targeted by the intervention (information the students were not aware of).

The sample used in the study was not a socioeconomic representation of British youth because only one independent (private) school in Oxfordshire was involved. Nevertheless, the type of students involved in the study are of particular interest to researchers as they were individuals who had chosen not to participate in traditional team sports. Adolescents uninterested in team sports at school may be at risk for dropping out of all types of activity when schools do not provide alternatives. It has been suggested that the decrease in time allocated to PE in recent years is a direct result of student and parent dissatisfaction with PE programs that continue to focus on team sports rather than lifetime activities (Corbin, 2002). Literature depicting the impact of such activities on student level outcomes is limited, particularly in the United Kingdom. Finally, the researchers cannot discount the possibility of some diffusion of treatment. The study was conducted at one school and students used the same fitness center. Leakage may have attributed to the lack of statistically significant differences at follow-up.

\section{Acknowledgments}

The authors would like to thank the school, students, and staff at the study school for their support and involvement during the study period.

Manuscript submitted: December 2, 2005;

Revision accepted: April 8, 2006

\section{References}

Aarnio, M., Winter, T., Kujala, U., \& Kaprio, J. (2002). Associations of health related behaviour, social relationships, and health status with persistent physical activity and inactivity: A study of Finnish adolescent twins. British Journal of Sports Medicine, 36, 360-364.

Aaron, D.J., Storti, K.L., Robertson, R.J., Kriska, A.M., \& Laporte, R.E. (2002). Longitudinal study of the number and choice of leisure time physical activities from mid to late adolescence: Implications for school curricula and community recreation programs. Archives of Pediatrics and Adolescent Medicine, 156, 1075-1080.

Allison, K.R., Dwyer, J.J.M., \& Makin, S. (1999). Self-efficacy and participation in vigorous physical activity by high school students. Health Education and Behaviour, 26, 12-24.

Bandura, A. (1977). Self-efficacy: Toward a unifying theory of behavior change. Psychological Review, 84, 191-215. 
Bandura, A. (1986). Social foundations of thought and action: A social cognitive theory. Englewood Cliffs, N.J: Prentice-Hall.

Bandura, A. (1997). Self-efficacy: The exercise of control. New York: W.H. Freeman.

Baranowski, T., Anderson, C., \& Carmack, C. (1998). Mediating variable framework in physical activity interventions: How are we doing? How might we do better? American Journal of Preventive Medicine, 15, 266-297.

Baranowski, T., Bouchard, C., Bar-Or, O., Bricker, T., Heath, G., Kimm, S.Y., et al. (1992). Assessment, prevalence, and cardiovascular benefits of physical activity and fitness in youth. Medicine and Science in Sports and Exercise, 24(6 Suppl.), S237-247.

Baranowski, T., Perry, C.L., \& Parcel, G.S. (1997). Models of interpersonal health behaviour. In K. Glanz, Rimer, B.K. and Lewis, F.M. (Ed.), Health behaviour and health education (pp. 149-236). San Francisco: Jossey-Bass.

Biddle, S.J.H. (2001). Enhancing motivation in physical education. In G. C. Roberts (Ed.), Advances in motivation in sport and exercise (pp. 101-127). Champaign, IL: Human Kinetics.

Booth, M.L., Okely, A.D., Chey, T., Bauman, A.E., \& Macaskill, P. (2002). Epidemiology of physical activity participation among New South Wales schools students. Australian New Zealand Journal of Public Health, 26, 371-374.

Boreham, C.A., Twisk, J., Savage, M.J., Cran, G.W., \& Strain, J.J. (1997). Physical activity, sports participation, and risk factors in adolescents. Medicine and Science in Sports and Exercise, 29, 788-793.

Calfas, K., Sallis, J., Oldenburg, B., \& Ffrench, M. (1997). Mediators of change in physical activity following an intervention in primary care: Pace. Preventive Medicine, 26, 297-304.

Calfas, K.J., Sallis, J.F., Nichols, J.F., Sarkin, J.A., Johnson, M.F., Caparosa, S., et al. (2000). Project grad: Two-year outcomes of a randomized controlled physical activity intervention among young adults. American Journal of Preventive Medicine, 18, 28-37.

Cardinal, B.J., Jacques, K.M., \& Levy, S.S. (2002). Evaluation of a university course aimed at promoting exercise behaviour. Journal of Sports Medicine and Physical Fitness, 42, 113-119.

Cavill, N., Biddle, S., \& Sallis, J.F. (2001). Health enhancing physical activity for young people: Statement of the United Kingdom expert consensus conference. Pediatric Exercise Science, 13, 12-25.

Corbin, C.B. (2002). Physical activity for everyone: What every physical educator should know about promoting lifelong physical activity. Journal of Teaching in Physical Education, 21, 128-144.

Dale, D., \& Corbin, C.B. (2000). Physical activity participation of high school graduates following exposure to conceptual or traditional physical education. Research Quarterly for Exercise and Sport, 71, 61-68.

Dale, D., Corbin, C.B., \& Cuddihy, T.F. (1998). Can conceptual physical education promote physically active lifestyles? Pediatric Exercise Science, 10, 97-109.

Deforche, B., De Bourdeaudhuij, I., Tanghe, A., Hills, A.P., \& De Bode, P. (2004). Changes in physical activity and psychosocial determinants of physical activity in children and adolescents treated for obesity. Patient Education and Counselling, 55, 407-415.

Department of Health. (2004). At least five a week. London: Department of Health.

Dishman, R.K., Motl, R.W., Saunders, R., Felton, G., Ward, D.S., Dowda, M., et al. (2004). Self-efficacy partially mediates the effect of a school-based physical-activity intervention among adolescent girls. Preventive Medicine, 38, 628-636.

Dishman, R.K., Motl, R.W., Saunders, R., Felton, G., Ward, D.S., Dowda, M., et al. (2005). Enjoyment mediates effects of a school-based physical activity intervention. Medicine and Science in Sports and Exercise, 37, 478-487.

Dzewaltowski, D.A., Estabrooks, P.A., \& Glasgow, R.E. (2004). The future of physical activity behavior change research: What is needed to improve translation of research into health promotion practice? Exercise and Sport Sciences Reviews, 32, 57-63. 
Epstein, L.H., Paluch, R.A., Gordy, C.C., \& Dorn, J. (2000). Decreasing sedentary behaviors in treating pediatric obesity. Archives of Pediatrics and Adolescent Medicine, 154, 220-226.

Fardy, P.S., White, R.E., Haltiwanger-Schmitz, K., Magel, J.R., McDermott, K.J., Clark, L.T., et al. (1996). Coronary disease risk factor reduction and behaviour modification in minority adolescents: The PATH program. Journal of Adolescent Health, 18, $247-$ 253.

Fitzgibbon, M.L., Stolley, M.R., Dyer, A.R., VanHorn, L., \& KauferChristoffel, K. (2002). A community-based obesity prevention program for minority children: Rationale and study design for hip-hop to health jr. Preventive Medicine, 34, 289-297.

Garcia, A.W., Pender, N.J., Antonakos, C.L., \& Ronis, D.L. (1998). Changes in physical activity beliefs and behaviors of boys and girls across the transition to junior high school. Journal of Adolescent Health, 22, 394-402.

Goldfine, B.D., \& Nahas, M.V. (1993). Incorporating health-fitness concepts in secondary physical education curricula. Journal of School Health, 63, 142-146.

Gordon-Larsen, P., Nelson, M.C., \& Popkin, B.M. (2004). Longitudinal physical activity and sedentary behaviour trends: Adolescence to adulthood. American Journal of Preventive Medicine, 27, 277-283.

Hart, E.A., Leary, M.R., \& Rejeski, W.J. (1989). The measurement of social physique anxiety. Journal of Sport and Exercise Psychology, 11, 94-104.

Hillsdon, M., Foster, C., \& Thorogood, M. (2005). Interventions for promoting physical activity. The Cochrane Database of Systematic Reviews, 1 (Art. No.: CD003180, DOI: 10.1002/14651858.CD003180.pub2.).

Kelder, S.H., Perry, C.L., Klepp, K.K., \& Lytle, L.L. (1994). Longitudinal tracking of adolescent smoking, physical activity, and food choice behaviors. American Journal of Public Health, 84, 1121-1126.

Kohl, H., Fulton, J., \& Caspersen, C. (2000). Assessment of physical activity among children and adolescents: A review and synthesis. Preventive Medicine, 31, S54-S76.

Leslie, E., Fotheringham, M., Veitch, J., \& Owen, N. (2000). A university campus physical activity promotion program. Health Promotion Journal of Australia, 10, 51-54.

Lewis, B.A., Marcus, B.H., Pate, R.R., \& Dunn, A.L. (2002). Psychosocial mediators of physical activity behaviour among adults and children. American Journal of Preventive Medicine, 23(2S), 26-35.

Maia, J.A.R., Lefevre, J., Claessens, A., Renson, R., Vanreusel, B., \& Beunen, G. (2001). Tracking of physical fitness during adolescence: A panel study of boys. Medicine and Science in Sports and Exercise, 33, 765-771.

McKenzie, T.L., Nader, P.R., Strikmiller, P.K., Yang, M., Stone, E.J., Perry, C.L., et al. (1996). School physical education: Effect of the child and adolescent trial for cardiovascular health. Preventive Medicine, 25, 423-431.

Nahas, M.V., Goldfine, B., \& Collins, M.A. (2003). Determinants of physical activity in adolescents and young adults: The basis of high school and college physical education to promote active lifestyles. The Physical Educator, 60, 42-56.

National Institute of Standards and Technology \& Sematech. (2005). Nist/sematech ehandbook of statistical methods. Retrieved April, 2005, from http://www.itl.nist. gov/div898/handbook/

Neumark-Sztainer, D., Story, M., Hannan, P.J., \& Rex, J. (2003). New-moves: An obesitybased prevention program for adolescent girls. Preventive Medicine, 37, 41-51.

Neumark-Sztainer, D., Story, M., Hannan, P. J., Tharp, T., \& Rex, J. (2003). Factors associated with changes in physical activity: A cohort study of inactive adolescent girls. Archives of Pediatrics and Adolescent Medicine, 157, 803-810.

Oppenheim, A.N. (1992). Questionnaire design, interviewing and attitude measurement. London: Pinter. 
Patrick, K., Sallis, J.F., Prochaska, J.J., Lydston, D.D., Calfas, K.J., Zabinski, M.F., et al. (2001). A multicomponent program for nutrition and physical activity change in primary care: PACE+ for adolescents. Archives of Pediatrics and Adolescent Medicine, 155, 940-946.

Prochaska, J.J., Rodgers, M.W., \& Sallis, J.F. (2002). Association of parent and peer support with adolescent physical activity. Research Quarterly for Exercise and Sport, 73, 206-210.

Reilly, J.J., \& McDowell, Z.C. (2003). Physical activity interventions in the prevention and treatment of paediatric obesity: Systematic review and critical appraisal. Proceedings of the Nutrition Society, 62, 611-619.

Rifas-Shiman, S.L., Gillman, M. W., Field, A.E., Frazier, A.L., Berkey, C.S., Tomeo, C.A., et al. (2001). Comparing physical activity questionnaires for youth: Seasonal vs annual format. American Journal of Preventive Medicine, 20, 282-285.

Saakslahti, A., Numminen, P., Salo, P., Tuominen, J., Helenius, H., \& Valimaki, I. (2004). Effects of a three-year intervention on children's physical activity from age 4 to 7 . Pediatric Exercise Science, 16, 167-180.

Saelens, B.E., Sallis, J.F., Wilfley, D.E., Patrick, K., Cella, J.A., \& Buchta, R. (2002). Behavioural weight control for overweight adolescents initiated in primary care. Obesity Research, 10, 22-32.

Sallis, J.F. (2000). Age-related decline in physical activity: A synthesis of human and animal studies. Medicine \& Science in Sports \& Exercise, 32, 1598-1600.

Sallis, J.F., Buono, M., J., Roby, J.J., Micale, F.G., \& Nelson, J.A. (1993). Seven-day recall and other physical activity self-reports in children and adolescents. Medicine and Science in Sports and Exercise, 25, 99-108.

Sallis, J.F., Calfas, K.J., Alcaraz, J.E., \& Gehrman, C. (1999). Potential mediators of change in a physical activity promotion course for university students: Project GRAD. Annals of Behavioral Medicine, 21, 149-158.

Sallis, J.F., \& Owen, N. (1999). Physical activity and behavioural medicine. London: Thousand Oaks, Sage.

Sallis, J.F., Taylor, W.C., Dowda, M., Freedson, P.S., \& Pate, R.R. (2002). Correlates of vigorous physical activity for children in grades 1 through 12: Comparing parentreported and objectively measured physical activity. Pediatric Exercise Science, 14, 30-44.

Saxena, R., Borzekowski, D.L.G., \& Rickert, V.I. (2002). Physical activity levels among urban adolescent females. Journal of Pediatric and Adolescent Gynecology, 15, 279284.

Schneider- Jamner, M., Spruijt-Metz, D., Bassin, S., \& Cooper, D.M. (2004). A controlled evaluation of a school-based intervention to promote physical activity among sedentary adolescent females: Project fab. Journal of Adolescent Health, 34, 279-289.

Schneider-Jamner, M., Spruijt-Metz, D., Bassin, S., \& Cooper, D.M. (2004). A controlled evaluation of a school-based intervention to promote physical activity among sedentary adolescent females: Project FAB. Journal of Adolescent Health, 34, 279-289.

Simon, C., Wagner, A., DiVita, C., Rauscher, E., Klein-Platat, C., Arveiler, D., et al. (2004). Intervention centred on adolescents' physical activity and sedentary behaviour (ICAPS): Concept and 6-month results. International Journal of Obesity, 28(Supplement 3), S96-S103.

Sproston, K., \& Primatesta, P. E. (2003). Health survey for England 2002. Volume 1: The health of children and young people. London: The Stationery Office.

Stevens, J., Story, M., Ring, K., Murray, D. M., Cornell, C.E., Juhaeri, et al. (2003). The impact of the pathways intervention on psychosocial variables related to diet and physical activity in American Indian schoolchildren. Preventive Medicine, 37(Supplement 1), S70-S79. 
Strauss, R.S., Rodzilsky, D., Burack, G., \& Colin, M. (2001). Psychosocial correlates of physical activity in healthy children. Archives of Pediatrics and Adolescent Medicine, 155, 897-902.

Taylor, W.C., Sallis, J.F., Dowda, M., Freedson, P.S., Eason, K., \& Pate, R.R. (2002). Activity patterns and correlates among youth: Differences by weight status. Pediatric Exercise Science, 14, 418-431.

Timperio, A., Salmon, J., \& Ball, K. (2004). Evidence-based strategies to promote physical activity among children, adolescents and young adults: Review and update. Journal of Science and Medicine in Sport, 7(Supplement 1), 20-29.

Trost, S.G., Owen, N., Bauman, A.E., Sallis, J.F., \& Brown, W. (2002). Correlates of adults' participation in physical activity: Review and update. Medicine and Science in Sports and Exercise, 34, 1996-2001.

Twisk, J.W.R., Kemper, H.C.G., van Mechelen, W., Post, G.B., \& van Lenthe, F.J. (1998). Body fatness: Longitudinal relationship of body mass index and the sum of skinfolds with other risk factors for coronary heart disease. International Journal of Obesity, 22, 915 .

U.S. Department of Health and Human Services. (1996). Physical activity and health: A report of the surgeon general. Atlanta, GA: U.S. Department of Health and Human Services, Centers for Disease Control and Prevention, National Center for Chronic Disease Prevention and Health Promotion.

U.S. Department of Health and Human Services \& U.S. Department of Agriculture. (2005). Dietary guidelines for Americans 2005. Retrieved February 2005, from http://www. healthierus.gov/dietaryguidelines

U.S. Department of Health and Human Services. (2000). Healthy people 2010: Understanding and improving health (2nd ed.). Washington D.C.: U.S. Government Printing Office.

Van Sluijs, E.M.F., Van Poppel, M.N.M., Twisk, J.W.R., Brug, J., \& Van Mechelen, W. (2005). The positive effect on determinants of physical activity of a tailored, general practicebased physical activity intervention. Health Education Research, 20, 345-356.

Vandogen, R., Jenner, D.A., Thompson, C., Taggart, A.C., Spickett, E.E., Burke, V., et al. (1995). A controlled evaluation of a fitness and nutrition intervention program on cardiovascular health in 10 to 12 year-old children. Preventive Medicine, 24, 9-22.

Welk, G.J., Corbin, C.B., \& Dale, D. (2000). Measurement issues in the assessment of physical activity in children. Research Quarterly for Exercise and Sport, 71, 59-73.

World Health Organization. (2005). Global strategy on diet, physical activity and health. Retrieved Accessed October 2005, from http://www.who.int/dietphysicalactivity/publications/facts/pa/en/ 